HNO 2020 68 (Suppl 2):S93-S99 https://doi.org/10.1007/s00106-020-00843-y Published online: 24 March 2020 (C) The Author(s) 2020

\author{
C. Dörfler ${ }^{1} \cdot$ T. Hocke $^{2} \cdot$ A. Hast ${ }^{1} \cdot$ U. Hoppe \\ 'Audiology Department and CI Centre CICERO Ear, Nose and Throat Clinic, University Hospital Erlangen, \\ Erlangen, Germany \\ ${ }^{2}$ Cochlear Deutschland GmbH \& Co. KG, Hannover, Germany
}

\title{
Speech recognition with hearing aids for 10 standard audiograms
}

\section{English version}

\section{Introduction}

Hearing loss is one of the five most frequent disorders with a substantial impact on quality of life [17]. In Germany, an estimated 10-12 million adults suffer from sensorineural hearing loss that requires treatment [23, 25] without any causal therapy available. As a rule, a hearing aid (HA) is indicated in such cases [24]. Here, the primary aim is an improvement of speech recognition in quiet and, in particular, in noise $[5,13]$. In addition to the indication, an evaluation of the hearing aid by an ear, nose, and throat (ENT) physician is also vitally important [10, 14, 23].

A previous study [7] investigated the relationship between unaided audiometric measures and speech recognition with hearing aids. Speech recognition in quiet was adopted as a surrogate parameter for success of the hearing aid provided. Speech recognition depends on hearing loss, hearing-aid fitting and age, among other factors [21]. It was also shown that the hearing-aided (HA) monosyllable recognition (word recognition score, WRS) at $65 \mathrm{~dB}$ sound pressure level (SPL), $\mathrm{WRS}_{65}(\mathrm{HA})$, for moderate and severe hearing loss is on average 20 percentage points below the maximum word recognition score

The German version of this article can be found under https://doi.org/10.1007/s00106019-00780-5.

The present work was performed by Constantin Dörfler in fulfillment of the requirements for obtaining the degree Dr. med. dent. at the Friedrich-Alexander-University Erlangen-Nürnberg (FAU).
$\left(\mathrm{WRS}_{\max }\right)$, as measured in the speech audiogram with headphones. For a sample of $n=181$ individuals provided with hearing aids, a statistical correlation was found between the mean of the hearing thresholds at $0.5,1,2$ and $4 \mathrm{kHz}$ (fourfrequency pure-tone average, 4FPTA) and the $\mathrm{WRS}_{\max }$ or $\mathrm{WRS}_{65}(\mathrm{HA})$ was found. This can be described by the following equations.

$$
\begin{aligned}
& \text { WRS }_{\max }[\%]= \\
& 100 \cdot \frac{e^{\left(\beta_{0}+\beta_{1} \cdot 4 F P T A\right)}}{1+e^{\left(\beta_{0}+\beta_{1} \cdot 4 F P T A\right)}}
\end{aligned}
$$

with $\beta_{0}=5.99 \pm 0.08$ and $\beta_{1}=-0.0793 \pm$ 0.0012

$$
\begin{aligned}
& \mathrm{WRS}_{65}(H A)[\%]= \\
& 100 \cdot \frac{e^{\left(\beta_{0}+\beta_{1} \cdot 4 F P T A\right)}}{1+e^{\left(\beta_{0}+\beta_{1} \cdot 4 F P T A\right)}}
\end{aligned}
$$

with $\beta_{0}=3.96 \pm 0.06$ and $\beta_{1}=-0.0673 \pm$ 0.0011

In other studies with hearing aid users, comparable values were found for the parameters $\beta_{0}$ and $\beta_{1}[12,21]$. For further analysis regarding the frequencydependent course of hearing loss, the proposed classification into 10 standard audiograms by Bisgaard et al. [1] seems appropriate. This classification is based on a statistical analysis of 28,244 hearing-threshold measurements; it was motivated by the requirements of German Institute for Norms (Deutsches Institut für Normung, DIN) EN 60118-15 and is intended to represent typical audiograms of hearing aid users. This DIN norm requires a realistic characterization of the hearing aids and the hearing aid setting. It therefore makes sense to apply these standard audiograms to clinical issues associated with hearing aid provision. All standard audiograms shown in - Fig. 1 show increasing hearing loss with increasing frequency. They have been classified into those with low to medium ( $N$-type, with a maximum decay of $20 \mathrm{~dB}$ per octave) and with strong (S-type with maximum decay of at least $25 \mathrm{~dB}$ per octave) frequency dependence. These types were subdivided into seven or three subtypes depending on the degree of hearing loss $\left(\mathrm{N}_{1}-\mathrm{N}_{7}\right.$ and $\left.\mathrm{S}_{1}-\mathrm{S}_{3}\right)$.

The aim of the present study was to investigate speech recognition with and without a hearing aid as a function of the extent and the frequency course of hearingloss for a large population of hearing aid users. In addition, the authors investigated the extent to which the earlier findings [7] also apply to a presentday population with modern hearing systems.

\section{Patients and methods}

\section{Patients}

In this retrospective study, 2357 hearing aid examinations were evaluated; these were performed between August 2012 and September 2017 in the Erlangen ENT Clinic, Germany. Bilateral hearing aid users with at least 3 months of hearing aid experience, German as mother tongue and a minimum age of 18 years were included. The exclusion criteria included abnormal otoscopic results, a mean air-bone gap at 0.5 , 1,2 and $4 \mathrm{kHz}$ of more than $5 \mathrm{~dB}$, an 

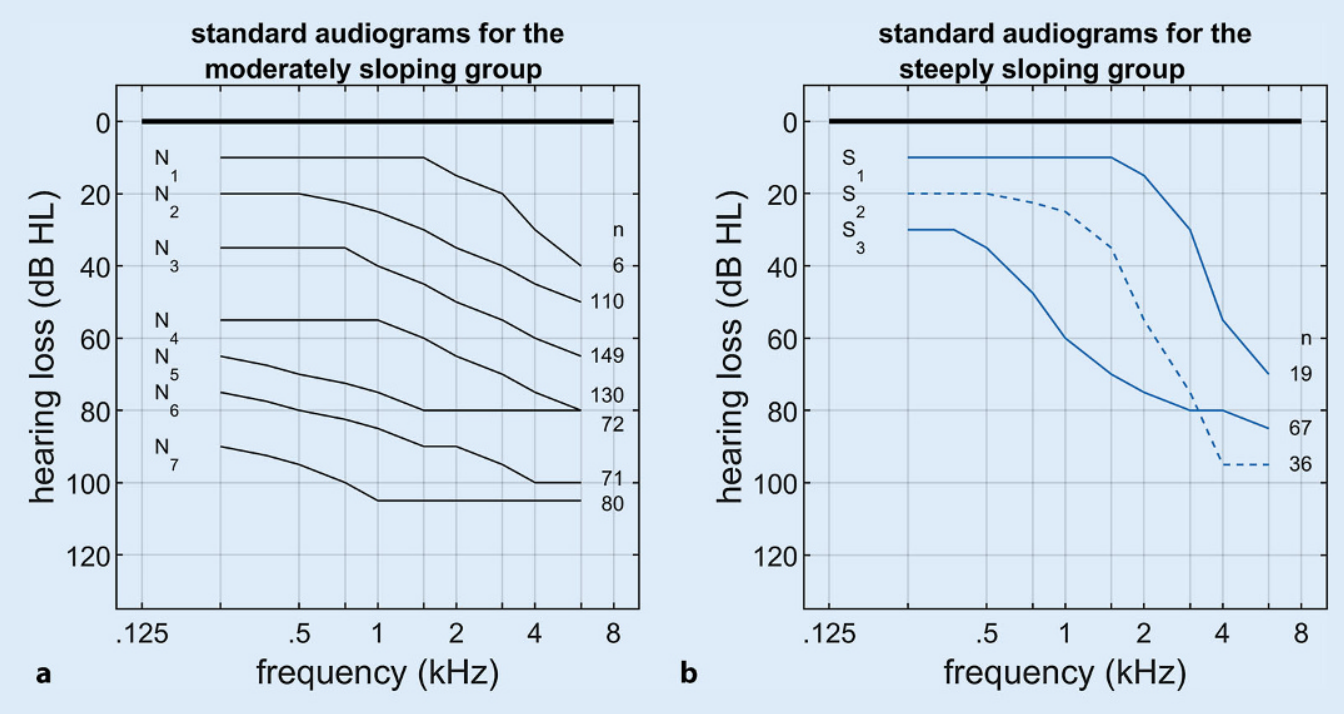

Fig. $1<$ Classification of pure-tone audiograms according to Bisgaard [1]. a Flat to moderately sloping audiograms. b Steeply sloping audiograms. The corresponding types $\left(\mathrm{N}_{1}-\mathrm{N}_{7}\right.$ or $\left.\mathrm{S}_{1}-\mathrm{S}_{3}\right)$ are shown to the left of the audiograms. To the right of the curves, the respective numbers of cases investigated here are noted

\begin{tabular}{|c|c|c|c|}
\hline \multicolumn{2}{|c|}{ Audiogram classification and group size } & \multirow{2}{*}{$\begin{array}{l}\begin{array}{l}\text { 4FPTA } \\
\text { (dB HL) }\end{array} \\
19 \pm 4\end{array}$} & \multirow{2}{*}{$\begin{array}{l}\text { Age (years) } \\
\text { (mean } \pm \text { SD) }\end{array}$} \\
\hline $\mathrm{N}_{1}$ & 6 & & \\
\hline $\mathrm{N}_{2}$ & 110 & $34 \pm 4$ & $65 \pm 11$ \\
\hline $\mathrm{N}_{3}$ & 149 & $47 \pm 4$ & $65 \pm 15$ \\
\hline $\mathrm{N}_{4}$ & 130 & $61 \pm 4$ & $66 \pm 16$ \\
\hline $\mathrm{N}_{5}$ & 72 & $74 \pm 6$ & $62 \pm 18$ \\
\hline $\mathrm{N}_{6}$ & 71 & $89 \pm 5$ & $60 \pm 16$ \\
\hline $\mathrm{N}_{7}$ & 80 & $109 \pm 8$ & $50 \pm 18$ \\
\hline $\mathrm{S}_{1}$ & 19 & $26 \pm 4$ & $62 \pm 23$ \\
\hline $\mathrm{S}_{2}$ & 36 & $46 \pm 7$ & $68 \pm 13$ \\
\hline $\mathrm{S}_{3}$ & 67 & $66 \pm 7$ & $65 \pm 15$ \\
\hline$S D S$ & & & \\
\hline
\end{tabular}

asymmetry of 4FPTA on both sides of more than $20 \mathrm{~dB}$ and any technical defects in the hearing aids. The data from a total of 740 ears from 370 users (182 men, 188 women) aged 21 to-98 years (mean, 62.8 years; standard deviation, 16.2 years) remained.

\section{Measurements}

Pure-tone air-conduction thresholds were measured for frequencies between 0.125 and $8 \mathrm{kHz}$ and bone-conduction thresholds between 0.25 and $6 \mathrm{kHz}$. The Freiburg monosyllable test was used to measure speech recognition. The measurements in quiet were performed with monaural presentation using headphones, initially at $65 \mathrm{~dB}$ SPL $\left(\mathrm{WRS}_{65}\right)$.
Subsequently, the presentation level was increased in increments of 5-15 dB until $100 \%$ speech intelligibility was attained (unless the sound level became intolerable for the user or the audiometer limit of $120 \mathrm{~dB}$ SPL was reached). The uncomfortable loudness level (UCL) corresponds to the lowest speech presentation level that is no longer tolerated. In addition to $\mathrm{WRS}_{65}, \mathrm{WRS}_{\max }$ was recorded.

The hearing aid check included a visual inspection and feedback provocation of oscillation. In addition, qualified personnel (hearing aid acousticians) checked whether the type and model of hearing aid provided were appropriate for the individual's hearing loss. The amplification was checked by measurement in situ. The speech test with hearing aid was conducted in free field at $65 \mathrm{~dB}_{\mathrm{SPL}}$ for the left and right ear separately; the contralateral side was adequately blocked with earplugs.

\section{Data analysis}

For all patients, the audiometric data of the 740 ears were analyzed for each side separately. Cases were classified according to their hearing-loss characteristics into the 10 audiogram types $\mathrm{N}_{1}-\mathrm{N}_{7}$ and $\mathrm{S}_{1}-\mathrm{S}_{3}$ according to Bisgaard [1] by using the minimum Euclidean distance.

For comparison of $\mathrm{WRS}_{\max }$ and $\mathrm{WRS}_{65}(\mathrm{HA})$ the difference

$$
D=m E V-E V_{65}(H G)
$$

and the quotient

$$
Q=\frac{E V_{65}(H G)}{m E V}
$$

were calculated for both quantities.

The quotient Q stands for the proportion of the $\mathrm{WRS}_{\max }$ that can be amplified by the hearing aid to give a speech perception of $65 \mathrm{~dB}$ SPL. It can be interpreted as the speech-audiometric efficiency factor of the hearing aid in question.

Logistical regression analysis of speech recognition, $\mathrm{WRS}_{\max }$ or $\mathrm{WRS}_{65}(\mathrm{HA})$, as a function of hearing loss, 4FPTA, was performed in a manner analogous to that described by Hoppe et al. [7]. The non-parametric Jonck- 
heere-Terpstra test was used to test the group trends within the two basic types of audiogram [4]. The statistical tests were carried out with SPSS V24 (IBM, Armonk, NY, USA), and the images were generated with Matlab $^{\circledR}$ R2017a (Mathworks, Natick/MA, USA).

\section{Results}

\section{Classification of Audiograms}

The 10 standard audiogram types, according to Bisgaard [1], are shown in - Fig. 1. The case numbers $(n)$ are shown to the right of the curves.

- Table 1 summarizes the group sizes and statistical measures for age and 4FPTA for each type of audiogram after classification of the 740 cases. The mean age in the individual groups varied from 50 years to 68 years.

- Fig. 2 shows the monaural speech recognition by the hearing aid users as box plots in relation to 4FPTA and audiogram type. The upper part (a) shows the results of the measurement with headphones at $65 \mathrm{~dB}$ SPL, while the middle part (b) shows the values measured in free field with hearing aids at $65 \mathrm{~dB}$ SPL. The lower part (c) shows the benefit from hearing aid provision as the difference between the two measurements. The data are presented for each audiogram type separately, with black box plots for $\mathrm{N}$ - type and blue box plots for S-type hearing loss.

For mild hearing loss $\left(\mathrm{N}_{1}, \mathrm{~N}_{2}\right.$ and $\left.\mathrm{S}_{1}\right)$ all hearing aid users achieved a $\mathrm{WRS}_{65}(\mathrm{HA})$ greater than $50 \%$. For moderate hearing loss $\left(\mathrm{N}_{3}\right.$ and $\left.\mathrm{S}_{2}\right)$, this was achieved in $75 \%$ of the cases. Of the users with severe hearing loss-groups $\mathrm{N}_{4}$ and $\mathrm{N}_{5}$, as well as $\mathrm{S}_{3}$-only a quarter had speech recognition scores above 50\%. For the groups $\mathrm{N}_{6}$ and $\mathrm{N}_{7}$, with profound hearing loss up to deafness, this $50 \%$ score was observed in only a few isolated cases: four out of 71 in the $\mathrm{N}_{6}$ group and one out of 80 in the $\mathrm{N}_{7}$ group. As shown in - Fig. 2c, users with hearing losses between 40 and $90 \mathrm{~dB}$ showed the greatest median improvements on provision of a hearing aid. However, $5.5 \%$ of the cases show reduced speech understanding in the free-field measurement with a hearing aid compared with the head-

HNO 2020 - 68 (Suppl 2):S93-S99 https://doi.org/10.1007/s00106-020-00843-y

(c) The Author(s) 2020

\section{Dörfler · T. Hocke · A. Hast · U. Hoppe}

\section{Speech recognition with hearing aids for 10 standard audiograms. English version}

\begin{abstract}
Background. Improvement of speech perception in quiet is an important goal of hearing aid provision. In practice, results are highly variable. The aim of this study was to investigate the relationship between type and extent of hearing loss (audiogram type), maximum word recognition score, and aided speech perception.

Materials and methods. Pure tone and speech audiometric data of 740 ears in 370 patients were reviewed. All subjects visited our hearing center for hearing aid evaluation between 2012 and 2017. The maximum word recognition score (WRS $\max$ ) and the monosyllabic speech recognition score with hearing aids, $\mathrm{WRS}_{65}(\mathrm{HA})$ were analyzed for 10 different standard audiogram types.

Results. The $\mathrm{WRS}_{65}(\mathrm{HA})$ with hearing aids for different degrees of hearing loss is, within error boundaries, comparable to previous
\end{abstract}

investigations and shows a difference of 10-20 percentage points to the WRS $S_{\max }$. This difference tends to be larger for flat and moderately sloping audiograms compared to steep-sloping audiograms. The ratio WRS $_{65}(\mathrm{HA}) / \mathrm{WRS}_{\max }$ can be interpreted as an efficiency factor for hearing aid provision, since it relates speech recognition with hearing aids to the maximally achievable information carrying capacity of the hearing impaired.

Conclusion. The expectation regarding hearing aid provision has to be adjusted according to maximum word recognition score, the derived quality measures, degree of hearing loss, and audiogram type.

\section{Keywords}

Maximum word recognition score $\cdot$ Speech audiometry · Tone audiometry · Speech comprehensibility · IEC 60118-15 phone measurement. This reduction was between 5 and 25 percentage points.

- Fig. 3 shows the correlation between the measured maximum word recognition score and the scores attained with a hearing aid. The $\mathrm{WRS}_{\max }$ for the individual groups is shown in - Fig. 3 a. - Fig. 3b,c represent the difference D and the quotient $\mathrm{Q}$, respectively, for each audiogram type. For values of $\mathrm{D}$ near zero and $Q$ near unity the $\mathrm{WRS}_{\max }$ is approximated by the $\mathrm{WRS}_{65}(\mathrm{HA})$. - Fig. 3a shows the reduction in maximum monosyllable recognition associated with increasing hearing loss. The differences shown in - Fig. 3 b reveal a similar picture, showing saturation effects of the test, as in - Fig. 2c. The calculation of the quotients Q is only possible for cases with $\mathrm{WRS}_{\max }$ greater than zero. For example, for the $\mathrm{N}_{6}$-type group, $\mathrm{WRS}_{\max }$ above zero was found in 60 of 71 cases. The corresponding results for the other groups are stated above the border of Fig. 3c. For the analysis of the influence of the audiogram type on $\mathrm{Q}$, the two basic types (N-type and S-type) were considered separately. The trend analysis for the medians was performed with the Jonckheere-Terpstra test. This results in a significant dependence of the efficiency $Q$ on the extent of hearing loss for both basic types. The test statistic J, the standardized test statistic $z$ and the corresponding $p$ value are: $J=36468, z=-11.7$ and $p<0.001$ for $\mathrm{N}$-type audiograms and $J=1020, z=-5.8$ and $p<0.001$ for S-type audiograms.

- Fig. 4 displays the present results in relation to earlier data from 2011 and 2012 [7]. The grey areas in the figure represent the $95 \%$ confidence interval of the logistical regression of the reference data [7]: dark grey for $\mathrm{WRS}_{\max }$ and light grey for $\mathrm{WRS}_{65}(\mathrm{HA})$. The results of the logistical regression of the $\mathrm{WRS}_{\max }$ or $\mathrm{WRS}_{65}$ (HA) are shown separately for $\mathrm{N}$-type and S-type hearingloss audiograms. The regression calculation was performed for $618 \mathrm{~N}$-type cases (ears) and for $122 \mathrm{~S}$-type cases. While the curves for $\mathrm{WRS}_{\max }$ of the N-type groups lie within the $95 \%$ confidence interval, the fit of $\mathrm{WRS}_{\max }$ for the S-type groups lies below the $95 \%$ confidence.

A different picture emerges for speech recognition with hearing aids: The two 


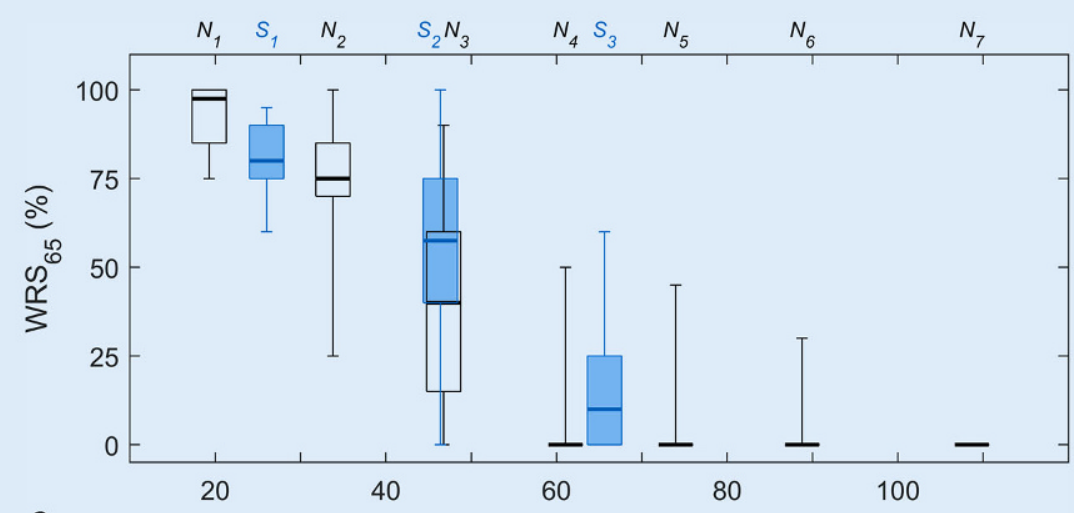

a
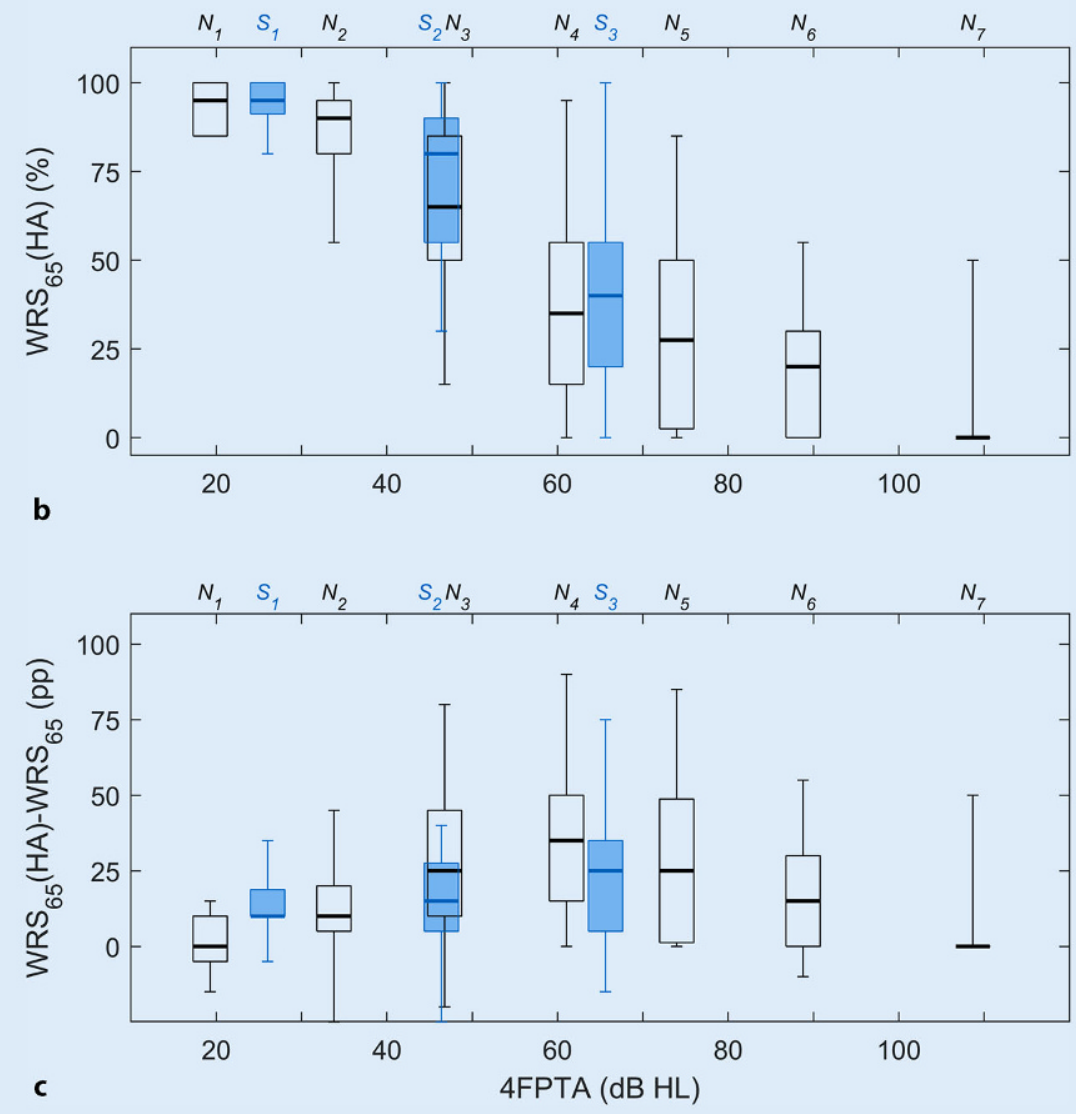

Fig. $2 \Delta$ Monaural speech recognition for the 10 audiogram types (black, N-type; blue, S-type), a without and $\mathbf{b}$ with hearing aid depending on four-frequency pure-tone average (4FPTA). The corresponding differences (percentage points) are shown in (c). The measurements without a hearing aid were made with headphones at $65 \mathrm{~dB}$ sound pressure level (SPL) and the hearing aid measurements were made in free field at $65 \mathrm{~dB}$ SPL. Each box plot shows the median, first/third quartiles, and minimum/ maximum. The x-position of a box plot corresponds to the mean 4FPTA of the cases that were assigned to the corresponding audiogram type (as listed in 0 Table 1)

regression functions for the $\mathrm{WRS}_{65}(\mathrm{HA})$ are largely within the $95 \%$ confidence interval, with a tendency toward better values for the S-type groups (severe hearing loss) compared with $\mathrm{N}$-type groups (mild to moderate hearing loss).

\section{Discussion}

The aim of this work was to investigate the correlation between the pure-tone and speech-audiometric measures as assessed during hearing aid evaluation. The focus was on: (i) understanding speech in quiet, (ii) the improvement through a hearing aid as the principal effect of hearingaid provision and (iii) the relationship to maximum monosyllable recognition. Extending the scope of previous work [7, $8]$, the cases were classified, on the basis of audiogram progression, according to the various audiogram types defined by Bisgaard [1]. For the same 4FPTA, monosyllabic word recognition with a hearing aid is significantly better for users with highly frequency-dependent hearing loss than for those whose audiograms show only moderate frequency dependence.

\section{Specific audiogram patterns and speech recognition}

$\mathrm{WRS}_{65}$, with or without a hearing aid, is primarily determined by the 4FPTA. For the $\mathrm{WRS}_{65}(\mathrm{HA})$, the type of audiogram provides additional information (see - Fig. 2b). $\mathrm{WRS}_{65}(\mathrm{HA})$ decays monotonically, in both $\mathrm{N}$ and $\mathrm{S}$ audiogram types, with increasing 4FPTA. However, the regression function for the hearing aids in patients with S-type audiograms is above the regression function for those with $\mathrm{N}$-type audiograms. In particular, a comparison of the $\mathrm{N}_{3}$ and $\mathrm{S}_{2}$ groups-with nearly equal 4FPTA and approximately equal age distribution-shows that the $\mathrm{WRS}_{65}(\mathrm{HA})$ for the S-type audiograms is 15 percentage points above the $\mathrm{WRS}_{65}(\mathrm{HA})$ for the $\mathrm{N}$-type audiograms. The results of the logistical regression support this finding: In low to moderate hearing loss, good speech recognition can be achieved with hearing aids, especially in cases where the audiogram is steep. While in the $S$ groups the steep drop in the audiogram in the headphone measurement of $\mathrm{WRS}_{\max }$ obviously leads to poorer results, the provision of a hearing aid compensates better for the frequency-specific attenuation component of hearing loss.

In the $\mathrm{N}$ groups, the frequency-independent amplification in the $\mathrm{WRS}_{\max }$ measurement thus corresponds more closely to the hearing-aid fitting than in the $\mathrm{S}$ groups, where low frequencies need no or only small amplification. This partly explains the differences in 


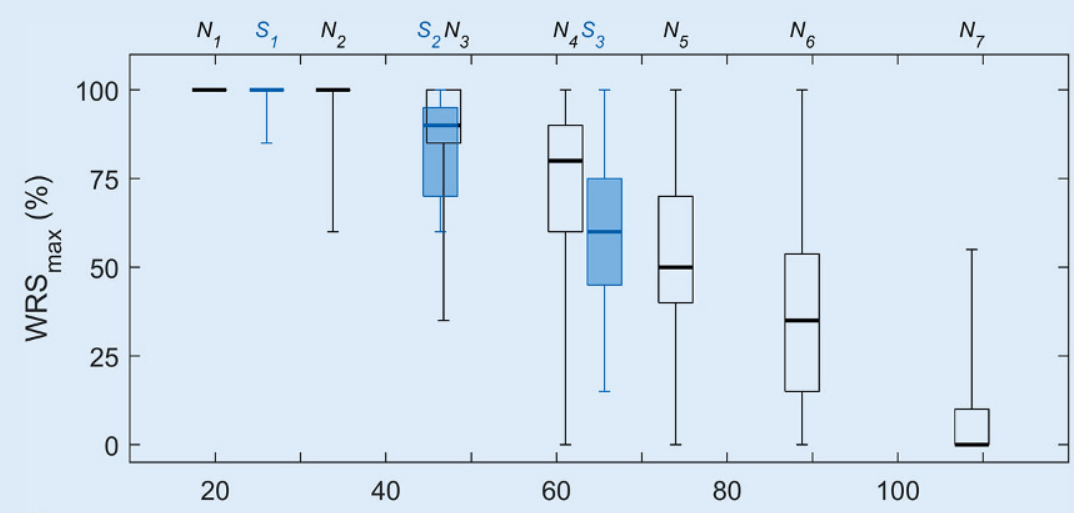

a

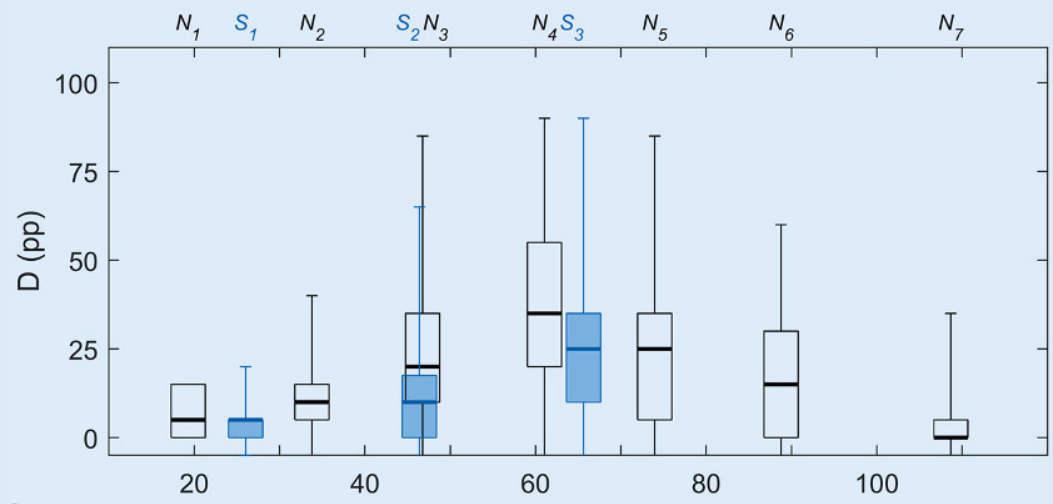

b

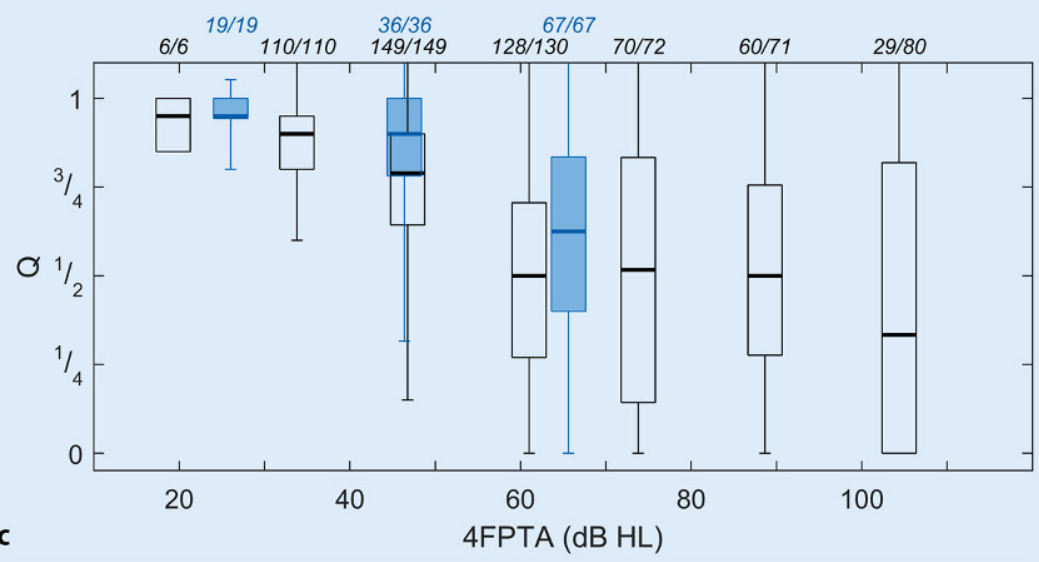

Fig. $3 \Delta$ Maximum monosyllable recognition $\left(W R S_{\max }\right)(\mathbf{a})$ and the relation to speech recognition $(\mathbf{b}, \mathbf{c})$ with hearing aid for the 10 types of audiogram (black, N-type; blue, S-type) depending on four-frequency pure-tone average (4FPTA); $\boldsymbol{b}$ shows the difference (percentage points) and $\boldsymbol{c}$ the ratio of the two measurements. The WRS $\max$ was measured with headphones and the hearing aid measurement in free field at $65 \mathrm{~dB}$ sound pressure level. The assignment of the box plots to the types of audiogram shown in - Fig. 1 is shown at the top. Each box plot shows the median, first/third quartiles and minimum/maximum. The x-position of a box plot corresponds to the mean 4FPTA of the cases that were assigned to the corresponding audiogram type. In the lower part (c), only those cases with WRS $\max _{\max }>0 \%$ can be displayed. The proportions of these cases in groups $\mathrm{N}_{1-7}$ and $\mathrm{S}_{1-3}$ are each given above the box plot in (c) the closeness of approach of $\mathrm{WRS}_{65}(\mathrm{HA})$ to $\mathrm{WRS}_{\max }$, as shown in $\bullet$ Fig. $3 \mathrm{c}$.

A further explanation could be the increasing availability of open-fit hearing aids in the last few years, for which the S-type audiograms are well suited in respect of the tonal-audiometric prerequisites [11]. An initially lower $\mathrm{WRS}_{\max }$ of the $S$ group can be compensated for by the advantages associated with the openfit design $[3,20]$.

\section{Comparison with previous investigations}

- Fig. 4 shows the results of the logistical regression for the $\mathrm{N}$ and $\mathrm{S}$ types. For specific 4FPTA regions, differences can be detected for the $\mathrm{N}$ - and S-type audiograms. However, in view of the far greater individual variation, the differences found in the regression are unlikely to entail major clinical consequences. Consequently, the reduction of the puretone hearing loss in 4FPTA seems to appropriately describe the description of the correlations with the measurements of recognition, at least for large groups of patients and the inferences drawn from their data $[7,8,12,15,21]$. The comparison of the aided speech recognition shown in 0 Fig. 4 with that in an earlier comparable population analysis for January 2011 to July 2012 [7] shows differences in the range of a few percentage points. Accordingly, no differences were observed for monosyllable recognition between the results of that study and the present results. This finding is consistent with that of a recent study [2] on subjective hearing quality.

\section{Practical aspects of hearing aid evaluation using speech audiometry}

Another aspect of the present work was the further description of the relationship between $\mathrm{WRS}_{\max }$ and $\mathrm{WRS}_{65}(\mathrm{HA})$ against the background of the speech audiometric evaluation of a hearing aid provision. The Guideline for Hearing Aids of the German Joint Federal Committee (Gemeinsamer Bundesausschuss) [5] requires an increase of $\mathrm{WRS}_{65}(\mathrm{HA})$ over $\mathrm{WRS}_{65}$ of at least 20 percentage points. 


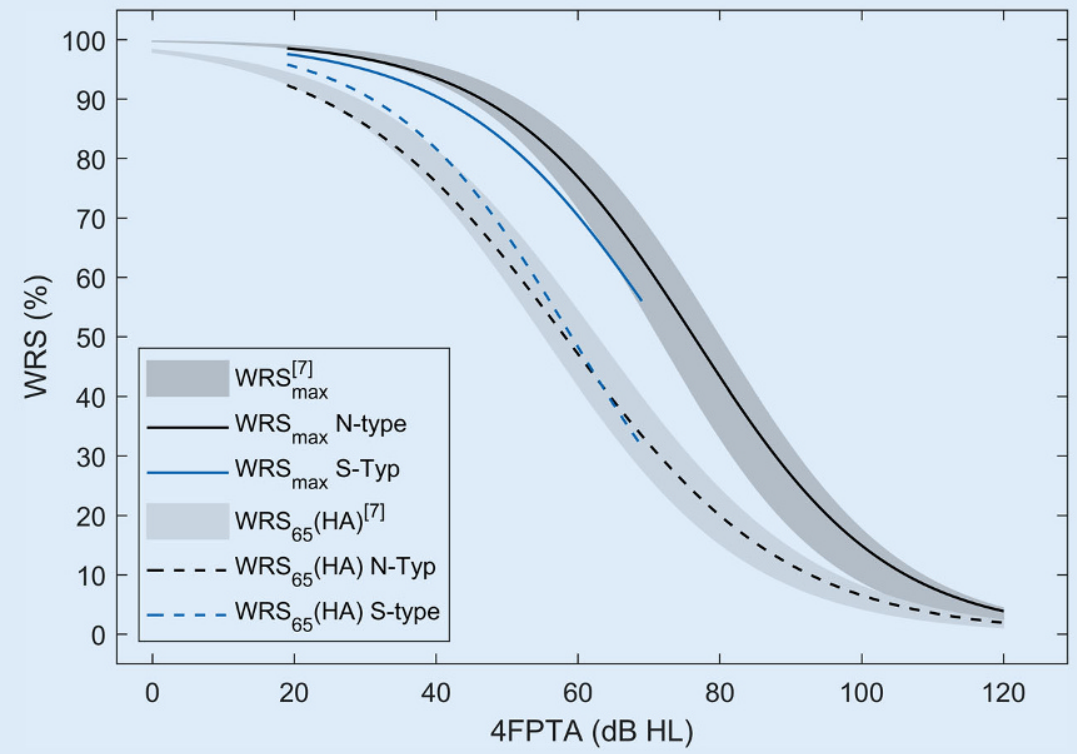

Fig. $4 \Delta$ Logistical regression of monosyllable recognition (WRS), maximum WRS (WRS $\max$ ) or hearing-aided WRS at $65 \mathrm{~dB}\left(W R S_{65}[\mathrm{HA}]\right)$ as a function of hearing loss, four-frequency pure-tone average (4FPTA), for $\mathrm{N}$ and S-type audiograms according to Bisgaard et al. [1]. The grey areas represent the $95 \%$ confidence interval of the logistical regression according to Hoppe et al. [7]. The black (blue) lines are the regression curves of the present data for the N-type (S-type) audiograms

Table 2 Speech-audiometric parameters for four cases in which the monosyllable recognition with hearing aid (WRS ${ }_{65}[\mathrm{HA}]$ ) was 10 percentage points below the maximum word recognition score $\left(W_{R S} \max \right)$. In these cases, the speech-audiometric efficiency factor $Q$ varied between 0 and 0.9

\begin{tabular}{lll|ll}
\hline Example & WRS $_{\max }$ & $\mathbf{W R S}_{\mathbf{6 5}}(\mathbf{H A})$ & $\mathbf{D}$ & $\mathbf{Q}$ \\
\hline$\# 1$ & 100 & 90 & 10 & 0.9 \\
$\# 2$ & 50 & 40 & 10 & 0.8 \\
$\# 3$ & 25 & 15 & 10 & 0.6 \\
$\# 4$ & 10 & 0 & 10 & 0
\end{tabular}

It also calls for $\mathrm{WRS}_{65}(\mathrm{HA})$ to converge with the $\mathrm{WRS}_{\max }$ as closely as possible, even if this is often not achieved [7, 8, 12, $15,21]$. The main reasons for this may be a lack of acceptance of the required acoustic amplification, overly low residual dynamics, reduced adaptation to the aid provided in elderly users or technical causes [3, 7, 21, 26]. Only for hearing losses below $40 \mathrm{~dB}$ and above $100 \mathrm{~dB}$ are the differences between $\mathrm{WRS}_{\max }$ and $\mathrm{WRS}_{65}(\mathrm{HA})$ below 20 percentage points for the majority of hearing aids provided. For these areas, the known floor and ceiling effects of the language test used will necessarily limit the difference, and thus its diagnostic value.

For mild to moderate hearing loss, most hearing aids can achieve an effi-
$\mathrm{WRS}_{\max }$ is not achieved. The efficiency Q quantifies the actually attained proportion of the greatest possible speech recognition (information-carrying capacity [6, 9]) and can be used, in addition to the difference, for the assessment of a hearing aid.

The results presented here, obtained at a specialized ENT clinic with an associated hearing-aid and cochlear-implant centre, are confirmed by other work $[12,15,18,19,21]$ at similar centres. Nonetheless, there remains some uncertainty as to whether these results are representative of the overall hearing-aid provision to a wider user spectrum. Therefore, it would also be desirable to conduct user-oriented studies, outside large hearing centres, on the current state of hearing aid provision. To assess the comparability of results, these tests should adhere to speech-audiometric standards as proposed for clinical studies on hearing improvement [22], for example with active middle-ear implants [16]. These should also include, as far as possible, speechintelligibility measurements in noise.

\section{Practical conclusion}

- The ratio between speech understanding with the hearing aid, $\mathrm{WRS}_{65}(\mathrm{HA})$, and maximum word recognition score, $\mathrm{WRS}_{\max }$ measured with headphones, provides additional information on the speechaudiometric efficacy of the hearing aid.

- The efficiency of a hearing aid provision is on average higher with strongly frequency-dependent Stype audiograms than with the flatter N-type audiograms.

- For hearing losses below $60 \mathrm{~dB} \mathrm{HL}$, the efficiency is close to one; above $60 \mathrm{~dB}$ HL, on average, values of only $1 / 2$ are achieved.

\section{Corresponding address}

\section{Prof. Dr. Dr. U. Hoppe}

Audiology Department and $\mathrm{CI}$ Centre CICERO Ear, Nose and Throat Clinic, University Hospital Erlangen

Waldstraße 1, 91054 Erlangen, Germany

Ulrich.Hoppe@uk-erlangen.de 
Funding. Open Access funding provided by Projekt DEAL.

\section{Compliance with ethical guidelines}

Conflict of interest. C. Dörfler, T. Hocke, A. Hast and U. Hoppe declare that they have no competing interests.

All procedures performed in studies involving human participants or on human tissue were in accordance with the ethical standards of the institutional and/or national research committee and with the 1975 Helsinki declaration and its later amendments or comparable ethical standards. Informed consent was obtained from all individual participants included in the study. The study was approved by the Ethics Committee of the Friedrich-Alexander University of Erlangen (No. 162_17 BC).

Open Access This article is licensed under a Creative Commons Attribution 4.0 International License, which permits use, sharing, adaptation, distribution and reproduction in any medium or format, as long as you give appropriate credit to the original author(s) and the source, provide a link to the Creative Commons licence, and indicate if changes were made. The images or other third party material in this article are included in the article's Creative Commons licence, unless indicated otherwise in a credit line to the material. If material is not included in the article's Creative Commons licence and your intended use is not permitted by statutory regulation or exceeds the permitted use, you will need to obtain permission directly from the copyright holder. To view a copy of this licence, visit http://creativecommons.org/licenses/by/4.0/.

\section{References}

1. Bisgaard N, Vlaming MS, Dahlquist M (2010) Standard audiograms for the IEC 60118-15 measurement procedure. Trends Amplif 14:113-120

2. Braun B, Dietrich A, Akcicek B et al (2015) Hörgeräteversorgung. Folgen der Festbetragsverdoppelung auf Compliance, Ergebnisqualität und Zuzahlungen. HNO 63:850-856

3. Dillon H (2012) Hearing aids, 2 edn. Thieme, New York, Stuttgart

4. Field A (2013) Discovering statistics using IBMSPSS statistics, 4 edn. SAGE, Los Angeles

5. Gemeinsamer Bundesausschuss (2018) Hilfsmittel-Richtlinie über die Verordnung von Hilfsmitteln in der vertragsärztlichen Versorgung (HilfsmittelRichtlinie/HilfsM-RL) in der Neufassung vom 19. Juli 2018. BAnz AT 02.10.2018 B2. Gemeinsamer Bundesausschuss, Berlin

6. Halpin C, Rauch SD (2008) Clinical implications of a damaged cochlea: puretone thresholds vs information carrying capacity. Otolaryngol Head Neck Surg 140:473-476

7. Hoppe U, Hast A, Hocke T (2014) Sprachverstehen mit Hörgeräten in Abhängigkeit vom Tongehör. HNO 62:443-448

8. Hoppe U, Hast A, Hocke T (2015) Audiometrybased screening procedure for cochlear implant candidacy. Otol Neurotol 36(6):1001-1005

9. Hoppe U, Hocke T, Müller A, Hast A (2016) Speech perception and information-carrying capacity for hearing aid users of different ages. Audiol Neurotol 21(suppl 1):16-20

10. Hoppe U, Hesse G (2017) Hörgeräte: Indikationen, Technologie, Anpassung und Qualitätskontrolle. Laryngorhinootologie 96(S1):43-65

11. Kießling J (2018) Konventionelle Hörsysteme: Hörgeräte. In: Kießling J, Kollmeier B, Baumann $U$ (eds) Versorgung mit Hörgeräten und Hörimplantaten, 3 edn. Thieme, Stuttgart

12. Kronlachner M, Baumann U, Stöver T, Weißgerber T (2018) Untersuchung der Qualität der Hörgeräteversorgung bei Senioren unter Berücksichtigung kognitiver Einflussfaktoren. Laryngorhinootologie 97:852-859

13. Lesica NA (2018) Why do hearing aids fail to restore normal auditory perception. Trends Neurosci 41:174-185

14. Löhler J, Akcicek B, Wienke A, Hoppe U (2014) Komplikationen bei der Hörgeräteversorgung ohne HNO-Arzt. HNO 62:360-366

15. Maier H, Lenarz T, Dollezal LV, Busch S (2018) Direct acoustic cochlear implants lead to an improved speech perception gap compared to conventional hearing aid. Otol Neurotol 39:1147-1152

16. Maier H, Baumann U, Baumgartner WD et al (2018) Minimal reporting standards for active middle ear hearing implants. Audiol Neurootol 23:105-115

17. Mathers C, Smith A, Concha M (2000) Global burden of hearing loss in the year 2000 . Global burden of disease. World Health Organization, Geneva, $\mathrm{p} 130$

18. McRackan TR, Ahlstrom JB, Clinkscales WB et al (2016) Clinical implications of word recognition differences in earphone and aided conditions. Otol Neurotol 37:1475-1481

19. McRackan TR, Fabie JE, Burton JA et al (2018) Earphone and aided word recognition differences in cochlear implant candidates. Otol Neurotol 39:e543-e549

20. Mueller HG, Ricketts TA (2006) Open-canal fittings: ten take-home tips. Hear J 59:24-39

21. Müller A, Hocke T, Hoppe U, Mir-Salim P (2016) Der Einfluss des Alters bei der Evaluierung des funktionellen Hörgerätenutzensmittels Sprachaudiometrie. HNO 64:143-148

22. Müller J, Plontke SK, Rahne T (2017) Sprachaudiometrische Zielparameter in klinischen Studien zurHörverbesserung. HNO 65:211-218

23. Schuchardt W, Löhler J (2012) Hörgeräteversorgung ohne HNO-Arzt? HNO 60:823-826

24. Steffens T, Marcrum SC (2018) Fachärztliches Basiswissen zur Wirksamkeit von Hörgeräten in Abhängigkeit der Art und Pathophysiologie einer Hörstörung. HNO 66:122-127

25. von Gablenz P, Holube I (2015) Prävalenz von Schwerhörigkeit im Nordwesten Deutschlands: Ergebnisse einer epidemiologischen Untersuchung zum Hörstatus (HÖRSTAT). HNO 63:195-214

26. ZwartenkotJW,SnikAFM, MylanusEAM, Mulder JJS (2014) Amplification options for patients with mixed hearing loss. Otol Neurotol 35:221-226 